\title{
Território e saberes tradicionais: articulações possíveis no espaço escolar indígena
}

\section{Land and traditional knowledge: possible articulations in the indigenous school space}

\author{
Antonio Jacó Brand \\ Valéria Aparecida Mendonça de Oliveira Calderoni**
}

\begin{abstract}
Resumo: $\mathrm{O}$ artigo aborda as interferências dos processos históricos de desterritorialização e confinamento territorial entre os índios Kaiowá e Guarani, em MS, na produção e ressignificação dos seus conhecimentos/saberes tradicionais, além das possíveis dificuldades no seu eventual trânsito para os espaços escolares. Apoiado em Oliveira Filho (1999), Bhabha (2003), Sousa Santos (2005), Descola (1988), Melià; Grünberg e Grünberg (2008), entre outros, adotou-se como procedimento técnico-metodológico a revisão bibliográfica, privilegiando entrevistas com docentes indígenas. Conclusões iniciais apontam para a relevância do que acontece no território, em especial, as mudanças na organização social, para os processos relativos aos conhecimentos tradicionais indígenas. Instâncias internas reconhecidas como espaços relevantes nesse processo têm sido tensionados e sua importância reduzida. No entanto, persiste a forma indígena de ressignificar e traduzir seus conhecimentos, que perpassa, inclusive, as lutas pela quebra do confinamento historicamente imposto.

Palavras-chave: Território. Saberes tradicionais. Espaços escolares.
\end{abstract}

\begin{abstract}
Interferences are analyzed with regard to the historical processes of deterritorialization and territorial confinement among Kaiowá and Guarani populations in southern Mato Grosso, Brazil, on the production and re-signification of their traditional knowledge and wisdom and on possible difficulties in the eventual transition to school spaces. Foregrounded on Oliveira Filho (1999), Bhabha (2003), Sousa Santos (2005), Descola (1988), Melià; Grünberg and Grünberg (2008) and others, a review of the literature was undertaken as techno-methodological procedure with special reference to interviews with indigenous teachers. Partial results highlight the relevance of what happens inside the territory, especially the changes in social organization for processes related to traditional indigenous wisdom. Internal events, acknowledged as relevant spaces in the process, have had their importance reduced. Nevertheless, the indigenous way of reframing and translating their knowledge persists and pervades even the struggle against the historically imposed confinement.
\end{abstract}

Keywords: Territory. Traditional wisdom. School space.

\footnotetext{
* In Memoriam.

** Doutoranda do Programa de Pós-Graduação em Educação da Universidade Católica Dom Bosco. E-mail: <lela_13613@yahoo.com.br>
} 
Minhas raízes estão aqui, meus parentes são daqui. Senti que a questão da terra é o lugar onde a gente vive, que tem significado aquele lugar [...]. Aquela terra é única, não tem outra terra. Aquele espaço é único, não tem como substituir.

(Benites, 2010)

O trabalho apresenta resultados de pesquisas que buscam compreender como os processos históricos de desterritorialização ${ }^{1}$ e de confinamento territorial $^{2}$ verificados entre os índios Kaiowá e Guarani ${ }^{3}$, no Mato Grosso do Sul, interferem na produção, reprodução, tradução ${ }^{4}$ e/ou ressignificação dos conhecimentos/saberes tradicionais ${ }^{5}$ dessa população. Considerando o eventual tensionamento e comprometimento de instâncias e formas tradicionais de aprendizagem em decorrência dos processos de desterritorialização implicados no confinamento territorial imposto pela colonização, é importante discutir, ainda, os problemas para um eventual trânsito desses conhecimentos e saberes para a educação escolar, considerando especialmente as determinações da legislação específica sobre esse tema.

A Constituição Federal de 1988, ao excluir do arcabouço legal toda referência à integração, garante aos povos indígenas, além das terras de ocupação tradicional, o direito à organização social, bem como a costumes, línguas, crenças e tradições. Além disso, buscando trazer para o campo da educação es-

\footnotetext{
${ }^{1}$ Por desterritorialização entendemos aqui o processo de retirada compulsória dos Kaiowá e Guarani de suas aldeias e territórios específicos, tendo em vista o projeto governamental de seu confinamento nas reservas demarcadas pelo Serviço de Proteção aos Índios (SPI), liberando as terras de ocupação tradicional para a colonização.

${ }^{2}$ Definimos confinamento como o processo histórico de ocupação do território por frentes não indígenas, que se seguiu à demarcação das reservas indígenas, em MS, pelo SPI, forçando a transferência dessa população para espaços definidos pelo Estado como posse indígena. Indica, portanto, o processo de progressiva passagem de um território indígena amplo, fundamental para a viabilização de sua organização social, para espaços exíguos, definidos tendo como perspectiva a integração dessa população, prevendo-se sua progressiva transformação em pequenos produtores ou assalariados a serviço dos empreendimentos econômicos regionais (BRAND, 1997).

${ }^{3}$ Segundo a classificação recorrente na antropologia, são designados pela classificação genérica de Guarani os grupos étnicos Kaiowá, Mbya e Ñandeva, sendo que, no cenário de relações interétnicas, no Mato Grosso do Sul, somente esses últimos, os Ñandeva, se autorreconhecem como Guarani, sendo tratados desta forma no presente texto. Embora em menor número, os Guarani/Ñandeva constituem a população majoritária em quatro terras indígenas, porém estão presentes, em menor número, em diversas outras. Ao nos referirmos a aspectos comuns aos dois utilizaremos a expressão Kaiowá e Guarani.

${ }^{4} \mathrm{O}$ conceito de tradução não se refere aqui a traduções no âmbito da linguística, mas às estratégias e processos de mediação ou de negociação de sentidos no esforço de tornar possíveis o diálogo e a compreensão, ou, ainda, segundo Pompa (2003), o esforço de tomarem e transformarem "para si" o que se apresentava como "outro".

${ }^{5}$ Poderíamos traduzir saber tradicional como conhecimento local, associado à cultura e às práticas sociais que se desenvolvem e reproduzem sem um esforço deliberado para tal. É um saber que, segundo Muñoz (2003, p. 285), vem de "práticas comunitárias do saber ser, saber estar, saber dar uso, de um mundo que se reconhece na convivência e nas práticas".
} 
colar indígena os direitos explicitados na Constituição Federal, vêm a Lei n ${ }^{\circ}$ 9.394/1996 - Lei de Diretrizes e Bases da Educação (BRASIL, 1996), o Decreto n o 6.861/2009 (BRASIL, 2009), que dispõe sobre Educação Escolar Indígena e sua organização em territórios etnoeducacionais, e a Resolução $\mathrm{CNE} / \mathrm{CEB} \mathrm{n}^{\mathrm{o}}$ 03/1999 (BRASIL, 1999), que fixa as diretrizes nacionais para as escolas indígenas, entre outros documentos legais.

A questão de fundo que investigamos diz respeito às relações e interferências dos processos de confinamento e de escasseamento, nesse território, de recursos naturais relevantes para o cotidiano indígena nos processos de produção, tradução e ressignificação de conhecimentos/saberes dessas populações.

Inúmeras são as pesquisas e produções acadêmicas, especialmente no âmbito da antropologia, que confirmam a inter-relação, amplitude e complexidade das mudanças no cotidiano de populações consideradas tradicionais ${ }^{6}$, em especial dos povos indígenas, decorrentes das interferências governamentais e não governamentais nos seus territórios ${ }^{7}$. Essas interferências se traduzem, especialmente, em desafios novos para a sustentabilidade, a organização social e a circulação dos saberes dessas populações.

Interessam-nos, neste trabalho, as mudanças na organização social, porque estas, como veremos, tensionam e questionam instâncias e espaços relevantes para os processos tradicionais de ensino e aprendizagem no cotidiano da aldeia. O território, como "entorno comunitário", na expressão de Muñoz (2003, p. 284), é "um âmbito carregado de significações, que a pessoa vai reconhecendo e registrando através da vida como esse espaço amplo de sentido e de dados para a sua percepção $[. . .]^{\prime \prime}$.

A pesquisa vem motivada pela crescente relevância dos conhecimentos/ saberes indígenas e dos processos próprios de aprendizagem enquanto componentes importantes em projetos de educação escolar indígena e cada vez mais no âmbito de projetos de formação de profissionais em nível superior demandados por esses povos $^{8}$. Essas iniciativas exigem estudos que possam fundamentar e sinalizar políticas que sejam mais adequadas a esses povos e atendam ao que

\footnotetext{
${ }^{6}$ O Decreto n. 6.040, de 2007 (BRASIL, 2007), que institui a política nacional de desenvolvimento sustentável dos povos e comunidades tradicionais, em seu art. $3^{\circ}$, estabelece que povos e comunidades tradicionais são grupos culturalmente diferenciados e que se reconhecem como tais, que possuem formas próprias de organização social, ocupam e usam territórios e recursos naturais como condição para sua reprodução cultural, social, religiosa, ancestral e econômica, utilizando conhecimentos, inovações e práticas gerados e transmitidos pela tradição.

${ }^{7}$ Cabe citar Oliveira Filho (1999), Brand (1997), Pereira (2004), Mura (2006), Silva (2007), entre outros.

${ }^{8}$ O Mato Grosso do Sul tem hoje um significativo número de acadêmicos indígenas (cerca de 800 ) nos mais diversos cursos (em especial, direito, enfermagem, história, pedagogia, entre outros) e instituições, com destaque especial para a Universidade Estadual do Mato Grosso do Sul (UEMS), em decorrência da política de cotas para indígenas.
} 
determinam as disposições legais, que reconhecem o direito dos povos indígenas a seus processos próprios de aprendizagem.

A Lei n. ${ }^{0}$ 9.394/1996, Lei de Diretrizes e Bases da Educação (LDB), assim dispõe: "O ensino fundamental regular será ministrado em língua portuguesa, assegurada às comunidades indígenas a utilização de suas línguas maternas e processos próprios de aprendizagem” (BRASIL, 1996, parágrafo 3º Art. 32, Secção III); e no artigo 78, Título VIII, ao referir-se à oferta de educação escolar bilíngue e intercultural aos povos indígenas, destaca, entre outros objetivos, que a União, em colaboração com as agências federais de fomento à cultura e de assistência aos índios, proporcionará aos índios, suas comunidades e povos, a recuperação de suas memórias históricas, a reafirmação de suas identidades étnicas e a valorização de suas línguas e ciências.

Escolhemos para esse estudo os Kaiowá e Guarani, em MS, especialmente a Terra Indígena Teý'ikue, localizada no município de Caarapó, região onde verificamos um dos mais radicais processos de desterritorialização e confinamento da atualidade. De outra parte, verificamos nessa terra indígena importantes avanços no que se refere à construção de uma escola de Ensino Fundamental e Básico efetivamente indígena, e nesse processo encontramos a atuação destacada de um grupo de professores da comunidade que participaram de cursos de formação de professores nos níveis médio e superior, específicos e direcionados para os povos de língua guarani.

Além de revisão bibliográfica, o trabalho inclui a discussão de alguns conceitos considerados relevantes, como território, territorialização, conhecimento ou saberes tradicionais, processos próprios de aprendizagem, entre outros; porém merece destaque especial a pesquisa de campo com ênfase no diálogo e entrevistas com docentes indígenas, todos já com formação em nível superior.

O texto compreende a introdução, uma breve descrição da situação dos Kaiowá e Guarani no MS com ênfase nos processos de desterritorialização e confinamento, e uma visita a alguns conceitos relacionados a essa discussão. Problematiza os processos de produção, tradução e ressignificação dos conhecimentos/saberes indígenas a partir da pesquisa realizada e traz algumas indicações conclusivas.

\section{Os Kaiowá e Guarani no MS e os processos de desterritorialização e confinamento}

O território tradicionalmente ocupado pelos Kaiowá e Guarani, no Sul do estado do Mato Grosso do Sul, situava-se entre o rio Apa (Bela Vista), Serra de Maracaju, rio Brilhante, rio Ivinhema, rio Paraná, rio Iguatemi e fronteira 
com o Paraguai (MELIÀ; GRÜNBERG; GRÜNBERG, 2008). Esses dois povos ocupavam esse amplo espaço de acordo com a disponibilidade de locais com recursos naturais considerados apropriados. Preferiam, por isso, estabelecer suas aldeias em áreas de mata e próximas a cursos de água. Além disso, o local teria que ser livre de ameaças sobrenaturais e de doenças e próximo a parentelas aliadas. Pesquisando a história recente dos Kaiowá e Guarani, percebemos que diversas aldeias foram por eles abandonadas em decorrência das muitas doenças, consequência já da presença de não indígenas em seu território.

Distribuíam-se em pequenos núcleos, constituídos por uma ou mais parentelas, sob a liderança dos ñanderu (nosso pai) ou tekoharmicha (chefe da aldeia), líderes de caráter marcadamente religioso, cujo poder estava apoiado no prestígio decorrente de seu parentesco, capacidade de convencimento e generosidade e não na força ou habilidade física. A identidade kaiowá e guarani remete diretamente à ideia de pertencimento étnico e às relações de parentesco. Esses núcleos macrofamiliares, que constituíam o que poderíamos caracterizar como aldeia (composta por um complexo de casas, roças e mata) e mantiveram, historicamente, características muito semelhantes, especialmente no que se refere à organização social, econômica, política e religiosa, eram relativamente autônomos.

Não obstante, uma característica importante no que se refere à relação dos Kaiowá e Guarani com o território é a sua mobilidade - oguata (caminhar), que constituía simultaneamente uma estratégia de manejo ambiental, evitando o esgotamento dos recursos naturais, e um importante expediente para o enfrentamento de doenças e/ou a superação de conflitos internos decorrentes de acusações de feitiço, disputas políticas, entre outras causas.

Em razão disto, as primeiras frentes não indígenas que adentraram no território a partir da década de 1880, após a Guerra do Paraguai, representadas pela Companhia Matte Larangeira' e pelos primeiros criadores de gado (estes últimos, no mesmo período se instalaram nos campos de Amambai, Ponta Porã e Bela Vista), na ótica dos Kaiowá e Guarani, não criaram maiores problemas, porque, ao não questionarem a posse da terra pelos índios, não interferiram na sua mobilidade. Essa situação, no entanto, alterou-se radicalmente com a instalação de colonos e projetos agropecuários no território indígena, a partir, especialmente, da década de 1950, pois estes questionam a presença indígena e exigem a sua transferência para outros espaços.

Entre os anos de 1915 a 1928, o Governo Federal demarcou para usufruto dos índios Kaiowá e Guarani um total de oito reservas de terra, perfazendo

\footnotetext{
${ }_{9}^{9}$ A Cia Matte Larangeira instala-se em todo o território ocupado pelos Kaiowá e Guarani, no Mato Grosso do Sul, após a Guerra do Paraguai, tendo em vista a exploração dos ervais nativos, abundantes em toda a região. Antes disso, em 1767, o Governo Português instalara, às margens do Rio Iguatemi, em pleno território kaiowá, o Forte Iguatemi (Povoaşão e Praça de Armas Nossa Senhora dos Pražeres e São Francisco de Paula do Iguatemi), de curta duração.
} 
18.124 hectares. Na demarcação, o Governo ignorou completamente os padrões indígenas de relacionamento com o território e seus recursos naturais e, principalmente, a sua organização social. A ação do Serviço de Proteção aos Índios (SPI), ao demarcar essas reservas, sinalizou e oficializou o processo de confinamento compulsório dos Kaiowá e Guarani, sedimentando a compreensão de que as terras indígenas por direito de posse eram, exclusivamente, as reservas demarcadas, liberando o restante das terras para serem transferidas a particulares através de títulos de propriedade.

Tem início, então, um amplo processo de desterritorialização e consequente confinamento de aldeias e grupos macrofamiliares. Em 1943, em pleno território indígena, o governo de Getúlio Vargas implantou a Colônia Agrícola Nacional de Dourados (CAND), e a partir da década de 1950 ampliou-se a instalação de empreendimentos agropecuários. Com o advento da soja e a utilização massiva da mecanização, no decorrer da década de 1970 agravou-se o comprometimento dos recursos naturais em toda a região, radicalizando-se o processo de confinamento dos Kaiowá e Guarani (BRAND, 1997).

A partir da década de 1980 a mão de obra indígena passou a ser canalizada para uma nova atividade econômica, cuja implantação iniciou-se no Estado do Mato Grosso do Sul e atualmente está em ampla expansão: a produção de açúcar e de álcool. Ao contrário do trabalho nos empreendimentos agropecuários, que se caracterizava pelo "esparramo" 10 , o trabalho nas usinas exige a concentração da força de trabalho indígena, sendo que as reservas demarcadas pelo SPI passaram a constituir-se em importantes reservatórios de mão de obra disponível para o exaustivo trabalho de corte da cana de açúcar.

O processo histórico de redução territorial e confinamento no interior das pequenas extensões de terra reservadas aos Kaiowá e Guarani gerou diversas mudanças e exigiu profundas atualizações no seu cotidiano, sendo apontado por pesquisadores e representantes indígenas como a causa de inúmeros problemas por eles vivenciados (PEREIRA, 2004), inclusive o acirramento da prática do suicídio $^{11}$. Esse processo precarizou profundamente a sustentabilidade dos índios aí localizados, os quais, crescentemente, vêm tornando-se dependentes das políticas de segurança alimentar do Governo e do aporte de recursos

\footnotetext{
${ }^{10}$ Esparramo, na expressão indígena, quer dizer dispersão dos grupos macrofamiliares, especialmente em decorrência da implantação dos projetos agropecuários.

${ }^{11}$ Há um significativo número de artigos e estudos já publicados sobre o tema dos suicídios, entre os quais se destacam autores como Melià (1994), Grünberg (1991), Azevedo (1987), Pereira (1995), Levcovitz (1994), Coutinho (1995), Morgado (1991), Wicker (1996) e Brand (1996), todos buscando compreender e explicar as razões que levariam os Kaiowá e Guarani a praticarem suicídios em número tão elevado como o verificado nos últimos anos. Segundo informações da SESAI (Secretaria Especial de Saúde Indígena), do Ministério da Saúde, entre os anos de 2000 e 2011 ocorreram 555 suicídios no MS, sendo que 99\% dos casos envolvem os Kaiowá e Guarani.
} 
externos. Além disso, transformou povos que, durante séculos, produziram alimentos não só suficientes, mas abundantes, como atesta a documentação histórica, em dependentes do fornecimento de cestas básicas e de toda a sorte de ajudas externas. Povos que foram importante mão de obra e contribuíram na implantação de grande parte dos empreendimentos agropecuários e públicos, como ferrovias e estradas no Mato Grosso do Sul, hoje nem conseguem prover a sua subsistência e a de suas crianças.

Além das consequências para a economia dos povos indígenas, esse processo de desterritorialização e confinamento criou problemas para a sua organização social, pois obrigou os núcleos macrofamiliares, autônomos, a buscarem abrigo nas reservas demarcadas pelo SPI, que, para administrar esses "ajuntamentos" de índios e aldeias, criou a figura dos capitães, líderes indígenas mais familiarizados com o modo de vida ocidental, nomeados, arbitrariamente, líderes máximos dentro das reservas; e para ajudá-los a exercer o poder e a manter a ordem sobre quem não tinham autoridade, foi criada também a polícia indígena ${ }^{12}$.

À medida que o território tradicional dessa população foi sendo ocupado pelas diversas frentes de exploração os grupos macrofamiliares foram sendo obrigados a se deslocar para dentro das reservas e, dessa forma, além de conviver e disputar lotes cada vez mais reduzidos com outros grupos macrofamiliares, tinham que submeter-se à autoridade de lideranças estranhas ${ }^{13}$.

Pesquisas e depoimentos indígenas indicam que nesse contexto são questionados e tensionados aspectos socioculturais tradicionais relevantes, como a organização social, a religião indígena, o universo mítico e místico e a autoestima ${ }^{14}$. Segundo Muñoz (2003, p. 284), "o sentido de pertencer vive através do enraizamento, na percepção do território e se expressa na linguagem, no costume, sempre em referência ao mundo natural". Neste sentido, pergunta-se: em que aspectos esse mesmo contexto interfere e que processos de produção, tradução e ressignificação dos conhecimentos ou dos saberes indígenas vem engendrando? Até que ponto as profundas interferências na

\footnotetext{
${ }^{12}$ Segundo o antropólogo Kaiowá Tonico Benites (2012), no passado, “cada família extensa vivia de forma autônoma no seu território ancestral de controle exclusivo e residia numa única habitação grande construída nas cabeceiras das minas da água e próximo dos rios, distanciando-se dez (10) e vinte (20) quilômetros de outra grande família. Nesta habitação e no seu entorno os adultos educavam os jovens e as crianças, sendo as atividades cotidianas educativas divididas segundo o sexo e a idade" (Trabalho digitado e apresentado em Seminário na Assembleia Legislativa de MS, em abril de 2012, com 3 p.).

${ }^{13}$ Para entender a importância dessa interferência na organização social dos Guarani e Kaiowá é preciso lembrar que a unidade social básica, sobre a qual estavam assentadas a economia, a organização social e a religião desses povos é a família extensa, que reunia parentes e agregados. Segundo Benites (2012), a família extensa é formada por pelo menos três gerações: avô, avó, filhos e filhas, genros e noras, netos e netas. Segundo o autor, esta organização social é administrada e representada por um líder político e um xamã ou líder religioso que perdura até os dias atuais.

${ }^{14}$ Ver Pereira (2004), Vietta (2007), Brand (1997), Silva (2007), entre outros.
} 
organização sociorreligiosa se traduzem em processos de abandono dos processos próprios de aprendizagem?

\section{Implicações conceituais relevantes para essa discussão}

A concepção de natureza e a relação desta com os homens são construções sócio-históricas e culturais e são relacionadas com a cosmovisão de cada povo, e nessas construções cada um deles encontra sua lógica explicativa. Nesse sentido, para compreender a relação entre a diversidade que caracteriza o mundo da natureza e o mundo da cultura, entendido aqui como o "mundo dos homens", é fundamental questionar a concepção dualista e hierarquizada que sustenta a visão ocidental, europeia e cristã de mundo e que perpassa os processos de ensino e aprendizagem da sociedade não indígena. Para Descola (1988, p. 132), os conceitos que vêm da tradição grega sempre incitam a ver na natureza uma "realidad exterior al hombre que éste ordena, transforma y transfigura".

Os Kaiowá, da aldeia de Panambizinho, município de Dourados-MS, relacionam o crescimento e o desenvolvimento dos meninos com o milho. Ambos dependem, para seu pleno amadurecimento, dos complexos rituais kunumi pepy avatikyry que ocupavam lugar relevante na vida de qualquer aldeia Kaiowa: "Así como en el avatikyry el maiz es una criatura, en el kunumi pepy los niños son como las plantas" (CHAMORRO, 1995, p. 118). Na mesma linha vai o depoimento de Jorge Paulo, da reserva de Caarapo, ao afirmar que "quando batiza planta parece criança quando vai ao doutor para tomar vacina. Aí não pega doença" (BRAND, 1997, p. 243); ou seja, o bom desenvolvimento das plantas depende da comunicação com os seus "donos", através da reza e das práticas rituais. Cavanha Paim, da mesma área indígena, reconhece que "vai deixando a reza e a planta e a chuva fica ruim" (BRAND, 1997, p. 245).

Sendo assim, a relevância do território, na ótica indígena, não se restringe aos recursos naturais, mas o território constitui um "recurso sociocultural" (RAMOS, 1986), com "dimensões sociopolítico-cosmológicas" (SEEGER; VIVEIROS DE CASTRO, 1979), e é, por isso, o espaço privilegiado de produção, tradução e ressignificação dos conhecimentos/saberes de cada povo. Esses conhecimentos decorrem da observação e experimentação cotidiana, sempre iluminada por uma visão cosmológica, na qual os mitos desempenham um papel relevante (BREMEN, 1987, p. 12-13). Segundo sua cosmologia, o homem não ocupa uma posição de superioridade nem de inferioridade, mas é parte integrante, razão pela qual, para estes povos, é fundamental conhecer a natureza, o que implica ir além do domínio de determinadas técnicas - de caça, pesca e coleta - e chegar à identidade e personalidade, ou ao espírito de cada ser vivo que a compõe, suas qualidades e sua função. 
No entendimento desses povos, há um sistema de trocas que não pode ser traduzido apenas como uma relação, mas que caracteriza uma interdependência entre os membros do mesmo grupo humano ou de grupos humanos distintos, e também entre estes e os ambientes naturais e tudo o que integra o cosmos. Huizer (1973 apud MUÑOZ, 2003, p. 286) afirma que "os mayas conceberam a sobrevivência como uma empresa coletiva na que o homem, a natureza e os deuses estão todos unidos através do sacrifício e da comunhão".

Por isso a natureza é muito mais que um manancial de recursos econômicos, portanto sua exploração não pode estar desvinculada da cultura, ou seja, dessas relações de troca e de produção simbólica que tudo inter-relacionam. É no território que se produzem e atualizam essas relações "sociais e simbólicas"; e o espaço que torna possível vivenciar a inter-relação entre os homens, a natureza e a sobrenatureza (RAMOS, 1986, p. 13).

A preocupação maior dos povos indígenas é "integrar-se da melhor maneira possível ao mundo existente, [...] procurando conhecer a sabedoria daquelas forças" (BREMEN, 1987, p. 15). Há uma diferença fundamental entre sua forma de entender a natureza e a forma ocidental. Para esses povos a comunicação com os espíritos ou os donos de cada ser é possível, visto que todos os seres da natureza "poseen algunos atributos de la humanidad" (DESCOLA, 1988, p. 132). Afirmava uma liderança da reserva indígena de Caarapó ${ }^{15}$ :

Quando a gente vai entrar no mato tem que fazer o jehovasa (se benzer), assim falar para o dono da mata para não olhar mal pra gente. Então, na época pra derrubar o mato, você tem que chegar ali e fazer assim, porque se derrubar a árvore sem estabelecer contato com o espírito da mata você fica doente (LIDERANÇA GUARANI, 2000).

Uma relação harmônica com a natureza exige também uma relação igualmente harmônica com os deuses. Nesse contexto, afirmava outra liderança indígena: "Tem casa grande, aí tem chicha, ai tá rezando, tudo ficou bem, o filho não tem briga com a mãe $[. .$.$] ". Como se pode notar nesse e em outros fragmentos das narrativas,$ o conhecimento construído por cada povo indígena sobre a natureza reflete essa sua busca de compreensão e entendimento, que vai sendo repassada de uma geração para a outra. Neste sentido, eles questionam a relação ocidental com a natureza e os recursos que ela disponibiliza, marcada pela busca constante de domínio e exploração, e propõem, ao invés, uma relação de reciprocidade e diálogo.

Walsh (2009, p. 15), referindo-se ao que denomina de "colonialidade cosmogônica" ou da mãe natureza, assentada "na diferença binária cartesiana entre

\footnotetext{
${ }^{15}$ Depoimento gravado durante oficina realizada em Caarapó, dia 9 de novembro de 2000, com um grupo de índios já mais idosos, acima de 50 anos.
} 
homem/natureza, categorizando como não modernas, 'primitivas' e 'pagãs' as relações espirituais e sagradas que conectam os mundos de cima e de baixo, com a terra e com os ancestrais como seres vivos", coloca uma nova dimensão da colonialidade, de grande relevância para as discussões neste trabalho.

Após descrever as dificuldades em compreender o conceito de território, Benites (2010) ${ }^{16}$ afirmou:

Minha família é aqui [...]. Minhas raízes estão aqui, meus parentes são daqui. Aí entendi o contexto (em que esse conceito foi construído). Senti que a questão da terra é o lugar onde a gente vive, que tem significado aquele lugar [...]. Aquela terra é única, não tem outra terra. Aquele espaço é único, não tem como substituir.

Concluindo, afirmou que o conceito de território que ele tem hoje, "como professor" depois de muito tempo, "é essa ideia de que a terra (território) é o lugar onde a gente vive, o lugar onde a gente cria significado a partir da nossa vivência". Segue afirmando que, "a terra não é somente o solo, mas toda a cosmologia, os sons e os ventos". Segundo Muñoz (2003, p. 288), "a vida que os indígenas reconhecem na natureza é tão diversa como a humanidade mesma".

Há importantes referências antropológicas dando conta da reciprocidade de qualquer ação sobre o território de um grupo ou povo ${ }^{17}$. Oliveira Filho (1999, p. 20), ao referir-se aos processos de territorialização como "processos de reorganização social", destaca como consequência a criação de uma nova unidade sociocultural, com mecanismos políticos especializados e a redefinição do controle social sobre os recursos ambientais, incluindo a reelaboração da cultura e da relação com o passado. Para esse autor, os processos de demarcação e definição de territórios acabam deflagrando "um amplo processo de reorganização sociocultural de amplas proporções” (OLIVEIRA FILHO, 1999, p. 21-22).

Poderíamos recorrer, ainda, a Barth (2000, p. 27), com seu entendimento das identificações étnicas como "categorias atributivas e identificadoras empregadas pelos próprios atores", com o objetivo de "organizar as interações entre as pessoas"; ou ainda, a Bhabha (2003, p. 63), quando afirma que a diferença cultural remete para "o processo da enunciação da cultura", entendida como algo permanentemente reinventado, recomposto e investido de novos significados, indicando para os modos próprios de cada grupo social ver e interagir com a realidade (FLEURI; SOUZA, 2005) ${ }^{18}$.

\footnotetext{
${ }^{16}$ Eliel Benites, docente e mestrando em educação.

${ }^{17}$ Para Oliveira Filho (1999, p. 20), a atribuição de uma "base territorial fixa se constitui em ponto-chave para a apreensão das mudanças", afetando o funcionamento das instituições e manifestações culturais.

${ }^{18}$ Bhabha (2003, p. 63) estabelece importante distinção entre o conceito de diversidade e diferença. A diversidade como "um objeto de conhecimento empírico" ou apenas o "reconhecimento de conteúdos e costumes culturais pré-dados", enquanto que a diferença é o "processo da enunciação da cultura como conhecível, legítimo", como um "processo de significação" ou de afirmação da identidade e/ou diferença.
} 
Por isso fica bastante evidenciado que o processo histórico de redução territorial e consequente confinamento no interior das pequenas extensões de terra gerou inúmeras mudanças e atualizações no cotidiano indígena, que vão muito além das transformações em sua economia e são decorrentes, em especial, da perda de recursos naturais importantes e mais facilmente percebidas pelo entorno regional.

Nada ficou de fora desse processo de busca de submissão dos Kaiowá e Guarani às demandas da economia regional. O confinamento, sendo uma ação do Estado enquanto articulador do processo de colonização, abrangeu o território indígena, seus modos de vida e sua organização social, economia e religião. As perdas territoriais, sob a ótica indígena, provocaram uma superpopulação nas reservas demarcadas pelo SPI ${ }^{19}$, e essa superpopulação provoca os maiores constrangimentos à organização social dos Kaiowá e Guarani.

Mura (2006, p. 108), fazendo referência ao depoimento de uma liderança kaiowá da TI Ñande Ru Marangatu, localizada no município de Antonio João, afirma que "à terra reduzida corresponde um modo de ser (teko) enfraquecido"; e prossegue: "um teko enfraquecido não pode contribuir adequadamente para a manutenção do equilíbrio cósmico". Por isso não há como passar ao largo desse processo histórico de confinamento para entender as mudanças verificadas na vida dessa população indígena nas últimas décadas.

\section{Processos de produção, tradução e ressignificação dos conhecimentos/saberes indígenas}

É importante atentar para a relevância das mudanças iniciadas na Constituição de 1988 no que se refere ao rompimento do projeto colonial de integração que pesava sobre o futuro dos povos indígenas. O questionamento no âmbito legal do projeto integracionista possibilitou também o progressivo questionamento do caráter homogeneizador e integracionista da escola imposta aos povos indígenas no bojo do mesmo projeto colonial. O processo de confinamento territorial veio acompanhado pela imposição do sistema escolar nacional, não indígena, o qual desempenhou, historicamente, papel importante nas políticas de integração dos índios à sociedade nacional.

Com base em uma pedagogia repressiva e profundamente enquadradora, as escolas buscavam "preparar" a criança indígena para uma vida em outra

\footnotetext{
${ }^{19}$ Cerca de $80 \%$ da população indígena seguem confinados nas oito reservas do SPI, sendo os casos mais graves de superpopulação são verificados nas Terras Indígena (TI) de Dourados, com 3.600 ha e uma população estimada em 13 mil índios, a TI de Caarapó, com o mesmo tamanho e cerca de cinco mil pessoas e a TI de Amambai com 2.450 ha e cerca de 7 mil índios. Segundo os padrões tradicionais, a população média de uma aldeia guarani era de 50 a 200 pessoas.
} 
realidade, desconectada de seu contexto social. A partir da década de 1980, tendo presentes as mudanças na Constituição Federal, os Kaiowá e Guarani iniciam um importante processo de quebra do confinamento, mediante a recuperação de parcelas do território indígena perdido para as frentes de colonização ${ }^{20}$, e as mesmas escolas, antes destinadas ao projeto de integração, são percebidas como espaços relevantes, desta vez no projeto indígena de afirmação étnica.

O Referencial Curricular Nacional para as Escolas Indígenas, publicado em 1998 pelo Ministério da Educação (MEC), com o objetivo de orientar a elaboração de projetos curriculares para as escolas indígenas do país, chama a atenção para o fato de se propor "apenas, subsidiar e apoiar os professores na tarefa de invenção e reinvenção contínua de suas práticas" (BRASIL, 1998, p. 14). Um ano após, a Resolução no 03, de 10 de novembro de 1999/CNE (BRASIL, 1999), sintetiza as conquistas legais na elaboração do conceito de educação escolar indígena no contexto da realidade atual desses povos no Brasil, fixa diretrizes para o funcionamento das escolas indígenas e dá outras providências. Nessa resolução é possível destacar os princípios e pressupostos que norteiam o novo ideário político-pedagógico desta escola.

Quanto ao esforço por permitir os deslocamentos necessários para uma escola indígena, cabe referir que a legislação brasileira sobre educação escolar indígena estabelece que devem ser resguardadas e valorizadas as "formas de conhecimento, processos próprios e métodos de ensino e aprendizagem" e, também, os "conteúdos curriculares especificamente indígenas e os modos próprios de constituição do saber e da cultura indígena" (BRASIL, 1999, Art. $3^{\circ}$ ), enfatizando, assim, as formas e modos de constituição desse saber.

Melià, referindo-se aos escritos de Nimuendaju sobre os Guarani, reconhece que o seu grande mérito foi não só o de colocar a palavra guarani no centro de sua investigação, mas de "haber tambien oido cómo el dice lo que dice" (MUNZEL, 1988 apud CHAMORRO, 1995, p. 31), referindo-se exatamente ao que hoje poderíamos entender como "processos próprios e métodos de ensino e aprendizagem".

Os conhecimentos ou saberes tradicionais produzidos e compartilhados por comunidades locais - indígenas ou não - incluem, certamente, as técnicas de manejo de recursos naturais, conhecimentos sobre ecossistemas, entre outros (SANTILLI, 2005); mas incluem, especialmente, o "mágico, o ritual, e enfim, o simbólico" (CASTRO, 2000, p. 167). Segundo essa autora, sua produção "faz parte da cadeia de sociabilidade e a ela é indissociavelmente ligada" ${ }^{\prime 2}$. Ou, ainda,

\footnotetext{
${ }^{20}$ Esse processo de recuperação territorial vem inserido num contexto mais amplo e abrangente de busca de recuperação de sua autonomia, mediante o fortalecimento das instâncias organizativas internas.

${ }^{21}$ Segundo Paz Grünberg (2010), em comunicação pessoal, verifica-se um "intercâmbio cotidiano" entre os Kaiowá e Guarani e a mata, que "os nutre" e que "nós não conhecemos e por isso não compreendemos". Sua
} 
segundo Muñoz (2003, p. 293), fazem parte desse saber indígena "diferentes estratégias e atitudes como, por exemplo, as de saber cuidar" (a natureza), que é "tarefa não somente humana", mas que compete, também, aos "Donos" dos animais e das plantas, que "se ocupam de vigiar para que nada se altere na ordem natural da vida na terra".

Esses conhecimentos são produzidos a partir da dinâmica da reciprocidade acima destacada, portanto não objetivam dominar e explorar os recursos naturais na perspectiva visualizada pelo ocidental, mas sim, compreender cada vez melhor a relação e os processos de comunicação entre as diversas realidades. Poderíamos recorrer aqui à concepção de saber trabalhada por Gauthier (1998, p. 182), apoiado em Schlanger (Une théorie du savoir, 1978), segundo a qual o saber é "uma relação do sujeito que conhece com seu mundo", resultante da interação "entre o sujeito e seu mundo". Assim, as alterações no território e, em especial, as imposições decorrentes desse processo colonial, entre as quais a superpopulação e as interferências na organização social e religiosa, ao questionarem e tensionarem a dinâmica da reciprocidade, questionam também os processos próprios de aprendizagem ou os processos de produção e tradução desses conhecimentos.

Segundo Gallois (2005) e Cunha (1999)22, a marca principal dos conhecimentos ou saberes tradicionais não é seu conteúdo ou sua antiguidade, mas a forma como estes são produzidos e reproduzidos/atualizados, um processo coletivo e acumulativo verificado no cotidiano dessas populações. Por isso Cunha (2009, p. 365) afirma que o tradicional diz respeito mais à "forma específica" de sua produção do que aos conteúdos; ou ainda: "tradicionais são seus procedimentos - suas formas, e não seus referentes". Nesse sentido, o que faz um grupo social ser identificado como tradicional é seu modo de vida ou as relações que segue estabelecendo com os outros, incluídos nesses outros os outros homens, a natureza e o sobrenatural.

Referindo-se ao conhecimento/saber tradicional, Cunha (1999) entende que, como qualquer saber, este é um "produto histórico" e, por isso, no "processo de investigação e recriação" enfrenta o problema da "erosão das condições de produção desse saber" (CUNHA, 1999, p. 156); e ao falar em erosão das condições de produção do conhecimento local ou tradicional, a autora refere-se à deterioração das "formas sociais das instituições que permitem esse tipo de ciência".

Essa erosão é confirmada pelos Kaiowá, da aldeia Tey’ikue. Dizia Benites (2010): "Há substituiçoes e perdas. Os mais velhos morrem e plantas se perdem, são destruídas.

preocupação sempre está nos espíritos que cuidam da natureza.

22 Palestra proferida no Instituto de Estudos Avançados da USP, em 17 de junho de 1998 e publicada em Estudos Avançados, v. 13, n. 36, 1999, sob o título "Populações Tradicionais e a Convenção da Diversidade Biológica”. 
A relação mudou". Poderíamos acrescentar que instituições sociais externas ao mundo indígena, como igrejas e escolas, criam raízes cada vez mais profundas dentro das aldeias, constituindo-se, na maior parte dos casos, em espaços de produção de saberes a partir de procedimentos e lógicas ocidentais, ou, se preferirmos, a partir de formas de relacionar-se com os outros homens e com as demais dimensões do universo que negam essas relações de reciprocidade.

Se é verdade que os processos envolvendo o território e seus recursos refletem-se na organização social, podemos concluir que esses processos se refletem também na produção e atualização dos conhecimentos tradicionais. Essas mudanças na organização social podem traduzir-se em erosão de condições específicas de transmissão dos conhecimentos. É o que confirmam os professores indígenas. O "saber é cotidiano", afirma Muñoz (2003, p. 294), "não somente como aprovação de técnicas e conhecimentos, mas porque também envolve a pessoa e o seu meio, a natureza, a vida vegetal e animal".

O docente kaiowá Lídio Cavanha (2011)23, após afirmar que a "globalização" já é bem forte na aldeia, conclui que o conhecimento tradicional indígena já não é mais ensinado como antes porque as próprias famílias já não ensinam mais; e quando os professores indígenas buscavam explicar o que denominaram de "atropelamento" dos conhecimentos tradicionais, sempre se reportavam aos conflitos na área da saúde ${ }^{24}$, porque, ao ignorar o conceito indígena de bem-estar, segundo o qual a doença mais importante é de ordem espiritual, as consequências, em sua visão, são desastrosas para as crianças, cuja alma pode a qualquer momento se assustar e deixar aquele corpo ${ }^{25}$. Segundo os docentes indígenas, muitas mortes acontecem porque na abordagem dos problemas de saúde se ignora e não se respeita o conhecimento tradicional.

Lembram que hoje plantas e animais desapareceram do território, que a criança sabe da existência desses animais pela televisão e não tem mais relação direta nem interage mais com eles. Tudo fica como um "conhecimento do passado", embora, ainda segundo os professores, persista a "relação desses animais com o nosso espírito". Este é um aspecto importante destacado por todos os que participaram dessa pesquisa. Entendem que "ainda persiste o interesse e o espírito" que orienta a vida indígena. Segundo o professor Otoniel (2011) ${ }^{26}$, "nossa vida é como fonte que foi soterrada", para, a seguir, e considerando o processo de

\footnotetext{
${ }^{23}$ Entrevista gravada e transcrita na Terra Indígena Tey’ikue. Município de Caarapó, em 2011.

${ }^{24}$ É no enfrentamento dos problemas relacionados à saúde e doença que mais claramente se manifestam as dificuldades de diálogo entre o conhecimento indígena e a medicina ocidental.

${ }^{25}$ Conforme Benites (2012, s. p.), "durante o primeiro ano de vida, antes de a criança pisar no chão, a alma é extremamente instável e insegura; transita entre o corpo e o lugar de origem, localizado no universo do Cosmo Guarani”.

${ }^{26}$ Entrevista gravada e transcrita na Aldeia Tey'ikue.
} 
construção de uma escola mais indígena, concluir que "agora estamos tirando a terra que estava soterrando, fazendo com que nós não valorizássemos a nossa cultura".

É certamente de grande relevância a explicação formulada pelos professores indígenas de que o objetivo principal das "retomadas de terras" e dos projetos de recuperação ambiental em andamento em algumas terras indígenas "não é por causa do gás carbônico", na expressão de um professor indígena, mas por causa do "significado" de retomar o conhecimento ${ }^{27}$, confirmando que se trata de um conhecimento ou de uma ciência que se baseia "na vida" dentro de um território e sociedade concreta, orientada por uma cosmovisão ou uma espiritualidade que, apesar das profundas mudanças, persiste.

Reiteraram os mesmos professores que a aprendizagem se dá na família e tudo está ligado à espiritualidade. "Se você acredita, está conectado", dizia o docente Cavanha (2011). Sob a ótica kaiowá e guarani, espiritualidade e conhecimento andam juntos. O antropólogo Benites (2012, s. p.), referindo-se à reciprocidade como "metodologia educativa", entende que ela transmite a "ideia de pertencimento à determinada família, fundamentada no princípio de dar e receber alguns bens materiais e imateriais"; e segue afirmando que essa prática começa com as crianças e é reforçada no decorrer do processo de formação do jovem e do adulto. Por isso, segundo os professores kaiowá e guarani, "quando o professor não aprende no berço ele traz essa deficiência para a escola". Aí temos certamente uma primeira dificuldade para o trânsito desses conhecimentos nos espaços escolares.

Os conhecimentos desses povos são profundamente contextualizados, e isto constitui uma diferença fundamental entre os dois conhecimentos, destacada pelos professores indígenas. Entendem que a dificuldade em lidar com o conhecimento ocidental vem do fato de ele ser "isolado", "centrado no detalhe", ao passo que o conhecimento indígena será tanto melhor quanto mais contextualizado for, e ao ser descontextualizado, acaba esvaziado. Daí a relevância da língua e dos processos próprios de aprendizagem como ferramentas pedagógicas ou epistemológicas e como elementos norteadores da prática pedagógica do diálogo entre sistemas distintos de conhecimento. Como povos "etnicamente diferentes" (BRAND, 2011), com saberes, fazeres, visão e experiências históricas diferentes, consequentemente, sistematizam seus conhecimentos de forma diferente.

Para que esse diálogo seja possível será necessário questionar a histórica "desqualificação" dos saberes tradicionais, considerados estáticos, exóticos ou apenas práticos e locais (SOUSA SANTOS, 2005). Colocados como desprovi-

\footnotetext{
${ }^{27}$ Os Kaiowá e Guarani vêm desenvolvendo um amplo processo de luta pela recuperação de parcelas de seu território perdidas durante o processo de colonização. Denominam essa ação como "retomada de terras", entendendo que se trata de terras que eram suas e que agora buscam reocupar.
} 
dos "de saber e cultura", seus saberes tradicionais foram, historicamente, marginalizados em nossa educação formal, ou foram incluídos nas margens. Neste contexto, é preciso "trazer o direito das diferentes formas de conhecimento a uma existência sem marginalização ou subalternidade por parte da ciência oficial" (SOUSA SANTOS, 2005, p. 30). Se o diálogo e o aconselhamento coletivo caracterizam a "lógica educativa" dos Kaiowá e Guarani, segundo o docente Benites (2010), será necessário, certamente, criar condições menos assimétricas nas relações no âmbito da educação escolar indígena.

\section{Indicações conclusivas}

Mesmo reconhecendo-se que ainda há um longo caminho a percorrer no que se refere a um maior aprofundamento das pesquisas sobre um tema tão complexo, algumas indicações conclusivas já são possíveis.

Uma primeira consideração diz respeito à relevância do que acontece no território para a produção e atualização dos conhecimentos indígenas e, por conseguinte, para a educação escolar. Os depoimentos indígenas parecem confirmar o que já vem constatado em diversas produções acadêmicas sobre esse tema: que está em curso um processo de erosão desses saberes/conhecimentos indígenas, decorrente não tanto das mudanças físicas verificadas no território, mas principalmente das transformações bastante profundas verificadas na organização social.

Instâncias internas reconhecidas pelos docentes indígenas como espaços relevantes para a produção e atualização dos conhecimentos, especialmente a família extensa, no caso dos Kaiowá e Guarani, têm seu papel tensionado e em muitos casos sua importância reduzida e questionada por outras instâncias sociais que adentraram nas aldeias em busca de espaços para divulgar suas mensagens a partir de suas lógicas ocidentais ou europeias. Essas outras instâncias, especialmente as próprias escolas, ao se orientarem por outras epistemologias, questionam, em muitos casos, a prática da educação indígena, apoiada em "experiências solidárias, compartindo saberes e habilidades, perante os olhares e ouvidos atentos dos demais" (MUÑOZ, 2003, p. 305-306).

Cumpre considerar que os processos de produção, atualização e ressignificação dos conhecimentos indígenas estão inseridos num sistema maior e mais abrangente de trocas ou de reciprocidades que, ao ser, por sua vez, questionado pelo entorno regional e pelas mesmas instituições acima - apoiadas em outras visões de mundo -, cria também dificuldades para que esses processos sigam fluindo no interior das comunidades indígenas. A pedagogia indígena é dialógica, pois "no mundo comunitário se aprende e se ensina fazendo", através da interação entre a pessoa que aprende e a que ensina. 
Não obstante, há outros aspectos a serem considerados num eventual trânsito desses conhecimentos para os espaços escolares. Para os Kaiowá e Guarani, o conhecimento só é possível e faz sentido quando contextualizado, e essa é uma diferença fundamental que os docentes indígenas percebem entre os dois conhecimentos, o indígena e o ocidental (europeu). Entendem que, descontextualizado ou retirado do cotidiano do território, o conhecimento indígena acaba esvaziado. Por isso, para os Kaiowá e Guarani, espiritualidade e conhecimento andam juntos.

Por outro lado, há um entendimento relevante destacado pela maioria dos que participaram dessa pesquisa. Referimo-nos à continuidade do "espírito" que orienta a vida indígena; ou seja, ainda persiste operando a forma especificamente indígena de produzir e atualizar os conhecimentos, confirmando o entendimento do professor Otoniel $(2011)^{28}$, que afirma: "[...] nossa vida é como fonte que foi soterrada". Otoniel afirma também que atualmente estão buscando "tirar a terra" historicamente acumulada sobre essa fonte.

Está efetivamente em curso um complexo processo de busca de apropriação e ressignificação do espaço escolar por parte das comunidades indígenas, a partir de projetos políticos e pedagógicos direcionados de forma cada vez mais clara para o fortalecimento étnico e para a busca de maior autonomia em relação ao entorno regional. Firma-se um grupo cada vez mais ativo de lideranças, e especialmente de docentes indígenas preocupados em construir uma escola mais comprometida e engajada com seus projetos de futuro; porém, passados alguns anos, ainda persistem, nesse processo de apropriação indígena dos espaços escolares, impasses e desafios que indicam os limites desse processo (BRAND, 2008).

O referencial homogeneizador e integracionista que orientou a educação escolar indígena ainda acaba sendo um marcador identitário de um mundo de significações e representações; entretanto esta integração e homogeneização esbarrou historicamente, como esbarra no presente, na dinamicidade dos sujeitos indígenas, com suas representações e processos próprios de aprendizagem, que tensionam os espaços e vêm abrindo brechas por onde os saberes tradicionais "vazam" e acabam por produzir outros significados, desestabilizando a normatização e a regulação instituída na escola.

Nestes momentos criam-se no espaço escolar indígena "ambientes intersticiais" ou "entrelugares" que, segundo Bhabha (2003), permitem transpor as narrativas de subjetividades originárias e focalizar os momentos de articulação das diferenças culturais. Os "entrelugares" concebidos por

\footnotetext{
${ }^{28}$ Entrevista gravada e transcrita na Aldeia Tey'ikue.
} 
Bhabha (2003, p. 20-21) propiciam o terreno para a elaboração de estratégias de subjetivação - singular e coletiva - que dão início a novos signos de identidade e lugares inovadores de contestação e colaboração, no ato de definir a própria ideia de sociedade. É nesses “entrelugares” que, apesar da "deterioração" e dos problemas acima apontados, vazam constantemente o "espírito" e as relações de reciprocidade que seguem orientando a vida indígena em territórios reduzidos e espaços tensionados por outras lógicas e os processos relacionados à produção e ressignificação de seus saberes/conhecimentos.

Essa percepção manifestada pelos docentes indígenas é de extrema importância e deve ser situada no amplo processo de afirmação étnica em curso, que perpassa e motiva a sua histórica luta pela quebra do confinamento que lhes foi imposto pela colonização. É o que se pode concluir da afirmação recorrente desses mesmos professores indígenas de que o objetivo principal das "retomadas de terras" e dos projetos de recuperação ambiental "não é por causa do gás carbônico", mas por causa do "significado" de retomar o conhecimento, confirmando a relevância do território enquanto espaço de afirmação sociocultural.

A identidade, segundo Silva (2000), é sempre relacional, e reflete, no caso dos Kaiowá e Guarani, importantes mudanças nas relações de poder regionais. Por isso as lutas desses indígenas pela recuperação de parcelas de seu território perdidas no decorrer da colonização devem ser situadas em um amplo processo de afirmação étnica, a partir do qual buscam redefinir, inclusive, a educação escolar em suas terras; e nesse contexto, para os Kaiowá e Guarani, adquire relevância estratégica o fortalecimento dos seus conhecimentos tradicionais e sua legitimação nos espaços escolares indígenas.

Não obstante, na construção de uma escola indígena na perspectiva desenhada pelos docentes persistem diversos outros desafios, que dizem respeito à dificuldade de diálogo e de reconhecimento por parte do entorno regional de suas historicidades distintas, indicando a persistência de relações de colonialidade, que seguem condicionando as relações com esses povos e dificultando a legitimação de suas epistemologias. Persistem, nesse entorno regional, relações de poder profundamente assimétricas que perpassam e impregnam as relações interétnicas na região. São essas relações de poder que geram e permitem compreender a violência que impera nas demandas territoriais no presente.

\section{Referências}

AZEVEDO, M. M. Jejuka - suicídio entre os kaiowá. Agosto, 1987. 11 p. Datilografado.

BARTH, F. Guru, o iniciador e outras variações antropológicas. Tradução de John Cunha Comerford. Rio de Janeiro: Contra Capa, 2000.

BENITES, T. O processo de educação básica das crianças guarani-kaiowa. 2012. 
Disponível em: <http://www.campograndenews.com.br/impressao/?_=\%2Fartigos $\% 2$ Foprocesso-de-educacao-basica-das-criancas-guarani-kaiowa>. Acesso em: 13 abr. 2012

BHABHA, H. O local da cultura. Belo Horizonte: Ed. da UFMG, 2003.

BRAND, A. Los Guaraníes en tiempos de suicidio. Acción, ano XXVIII, n. 168, p. 31-33, out. 1996.

O impacto da perda da terra sobre a tradição kaiowá/guarani: os difíceis caminhos da palavra. 1997. 382 f. Tese (Doutorado em História) - Pontifícia Universidade Católica do Rio Grande do Sul, Porto Alegre, 1997.

. Educação escolar e sustentabilidade indígena: possibilidades e desafios. Ciência e Cultura, Campinas, v. 60, n. 4, p. 25-28, 2008.

. Os acadêmicos indígenas e as lutas por autonomia de seus povos. In: SEMERARO, G. et al. (Org.). Gramsci e os movimentos populares. Niterói: UFF, 2011. p. 201-214.

BRASIL. Lei no 9.394, de 20 de dezembro de 1996. Estabelece as diretrizes e bases da educação nacional. Diário Oficial [da República Federativa do Brasil], Brasília, v. 134, n. 248, 23 dez. 1996. Seção I. p. 27834-27841.

. Ministério da Educação e do Desporto. Referencial Curricular Nacional para as Escolas Indígenas. Brasília: MEC/SEF, 1998.

Congresso. Senado. Resolução n 3, de 1999. Coleção de Leis da República Federativa do Brasil, Brasília, v. 183, p. 1156-1157, 1999.

Decreto $\mathrm{n}^{\circ}$ 6.040, de 07 de fevereiro de 2007. Institui a Política Nacional de Desenvolvimento Sustentável dos Povos e Comunidades Tradicionais. Diário Oficial da União, Brasília, 08 fev. 2007. Seção 1. p. 316.

. Decreto n. 6.861, de 27 de maio de 2009. Dispõe sobre a Educação Escolar Indígena, define sua organização em territórios etnoeducacionais, e dá outras providências. Diário Oficial da União, Brasília, 28 fev. 2009. Seção 1. p. 23.

BREMEN, V. V. Fuentes de caza y recolección modernas. Projectos de ayuda al dessarolo destinados a los indígenas del Gran Chaco. 1987.

CASTRO, E. Território, biodiversidade e saberes de populações tradicionais. In: DIEGUES, A. C. (Org.). Etnoconservação: novos rumos para a proteção de natureza nos trópicos. São Paulo: Hucitec, 2000.

CHAMORRO, G. Kurursu Ñe'ëngatu: palavras que la história no podría olvidar. Assunción: Centro de Estúdios Antropológicos/Instituito Ecumênico de Posgrado/COMIN, 1995. 235 p.

COUTINHO JR, W. Suicídio indígena no Mato Grosso do Sul. Relatório analítico apresentado à FUNAI/Ministério da Justiça. Brasília, nov. 1995. 29 p. Datilografado.

CUNHA, M. C. Populações Tradicionais e a Convenção da Diversidade Biológica. Estudos Avançados, São Paulo, v. 13, n. 36, p. 147-163, maio/ago. 1999. DOI: 10.1590/S010340141999000200008

. Cultura com aspas e outros ensaios. São Paulo: Cosac Naify, 2009. 
DESCOLA, P. La selva culta: simbolismo y praxis en la ecología de los Achuar. Tradução de Juan Carrera Colin y Xavier Catta Quelen. Quito: Abya-Yala, 1988.

FLEURI, R. M.; SOUZA, M. I. P. Entre os limites e limiares de culturas: educação na perspectiva intercultural. In: ENCONTRO NACIONAL DE DIDÁTICA E PRÁTICA DE ENSINO - Igualdade e Diversidade na Educação, 11., 2005, Goiânia. Anais... Goiânia, 2005.

GALLOIS, D. T. Cultura “indígena” e sustentabilidade: alguns desafios. Revista Tellus, ano 5, n. 8/9, p. 29-35, abr./out. 2005.

GRÜNBERG, G. Por que os Guarani/Kaiowá estão se matando? Tempo e presença, n. 37, p. 32-37, 1991.

GAUTHIER, J. Carta aos caçadores de saberes populares. In: MARISA, V. C. (Org.). Educação popular hoje. São Paulo: Loyola, 1998. p. 181-212.

LEVCOVITZ, S. Kandire: o paraíso terreal - uma investigação etnopsicanalítica sobre a produção da morte como fundamento das sociedades minimalistas. 1994. Tese (Doutorado em Psiquiatria) - Universidade Federal do Rio de Janeiro, Instituto de Psiquiatria, Rio de Janeiro, 1994.

MELIÀ, B. ¿Son los guaranies potencialmente suicidas?. Accion, ano XXVI, n. 144, p. 30-33, jun. 1994.

MELIÀ, B.; GRÜNBERG, G.; GRÜNBERG, F. Los Pãi Tavyterã: etnografia guarani del Paraguay contemporáneo. Asunción: CEADUC- CEPAG, 2008.

MORGADO, A. F. Epidemia de suicídio entre os Guarani-Kaiwá: indagando suas causas e avançando a hipótese do recuo impossível. Cadernos de Saúde Pública, Rio de janeiro, v. 7, n. 4, p. 585-597, out./dez. 1991. DOI: 10.1590/S0102-311X1991000400009

MUNOZZ, M. G. Saber indígena e meio ambiente: experiência de aprendizagem comunitária. In: LEFF, E. (Org.). A complexidade ambiental. São Paulo: Cortez, 2003.

MURA, F. À procura do "bom viver”: Território, tradição de conhecimento e ecologia doméstica entre os Kaiowá. 2006. 504 f. Tese (Doutorado em Antropologia Social) Programa de Pós-Graduação em Antropologia Social do Museu Nacional, Universidade Federal do Rio de Janeiro, v. I e II, 2006.

OLIVEIRA FILHO, J. P. Ensaios em antropologia histórica. Rio de Janeiro: Ed. UFRJ, 1999.

PEREIRA, L. M. Imagens Kaiowá do Sistema Social e seu Entorno. 2004. 2 v. 403 f. Tese (Doutorado em Ciência Social - Antropologia Social) - Universidade de São Paulo, São Paulo 2004.

PEREIRA, M. A. da C. Uma rebelião cultural silenciosa: investigação sobre os suicídios entre os Guaraní. Brasília: FUNAI, 1995. (Índios do Brasil, 3).

POMPA, C. Religião como tradução. Bauru: EDUSC, 2003.

RAMOS, A. Sociedades indígenas. São Paulo: Ática, 1986.

SANTILLI, J. Socioambientalismo e novos direitos. Proteção jurídica à diversidade biológica e cultural. São Paulo: Petrópolis, 2005. 
SEEGER, A.; VIVEIROS DE CASTRO, E. B. Terras e territórios indígenas no Brasil. Civilização Brasileira, v. 12, n. 1-2, p. 101-114, 1979.

SILVA, A. B. da. Mais além da “aldeia": território e redes sociais entre os Guarani de Mato Grosso do Sul. 2007. 255 f. Tese (Doutorado em Antropologia Social) - Programa de PósGraduação em Antropologia Social, Universidade Federal do Rio de Janeiro, Rio de Janeiro, 2007.

SILVA, T. T. Identidade e diferença: a perspectiva dos Estudos Culturais. 4. ed. Petrópolis: Vozes, 2000.

SOUSA SANTOS, B. de; MENESES, M. P. G.; NUNES, J. A. Para ampliar o cânone da ciência: a diversidade epistemológica do mundo. In: SOUSA SANTOS, B. de. (Org.). Semear outras soluções: os caminhos da biodiversidade e dos conhecimentos rivais. Rio de Janeiro: Civilização Brasileira; Ministério da Cultura, 2005. p. 21-45.

VIETTAA, K. Histórias sobre terra e xamãs Kaiowá: territorialidade e organização social na perspectiva dos Kaiowá de Panambizinho (Dourados, MS) após 170 anos de exploração e povoamento não indígena da faixa de fronteira entre o Brasil e o Paraguai. 2007. 512 f. Tese (Doutorado em Antropologia Social) - Universidade de São Paulo, São Paulo, 2007.

WALSH, C. Interculturalidade, crítica e pedagogia decolonial: in-surgir, re-existir e re-viver. In: CANDAU, V. M. (Org.). Educação intercultural na América Latina: entre concepções, tensões e propostas. Rio de Janeiro: 7 letras, 2009. p. 12- 42.

WICKER, H-R. Taruju: enfermedad de los dioses que lleva al suicidio. Assunção, 1996. Datilografado.

Recebido em 30/04/2012

Versão final recebida em 15/09/2012

Aceito em 28/10/2012 